\title{
Effect of crack pattern on the self-healing capability in traditional, HPC and UHPFRC concretes measured by water and chloride permeability
}

\author{
Alberto Negrini ${ }^{1,2}$, Marta Roig-Flores ${ }^{1, *}$, Eduardo J. Mezquida-Alcaraz ${ }^{1}$, Liberato Ferrara ${ }^{2}$, Pedro Serna ${ }^{1}$ \\ ${ }^{1}$ Universitat Politècnica de València, Instituto de Ciencia y Tecnología del Hormigón, Valencia, Spain \\ ${ }^{2}$ Politecnico di Milano, Milan, Italy
}

\begin{abstract}
Concrete has a natural self-healing capability to seal small cracks, named autogenous healing, which is mainly produced by continuing hydration and carbonation. This capability is very limited and is activated only when in direct contact with water. High Performance Fibre-Reinforced Concrete and Engineered Cementitious Composites have been reported to heal cracks for low damage levels, due to their crack pattern with multiple cracks and high cement contents. While their superior self-healing behaviour compared to traditional concrete types is frequently assumed, this study aims to have a direct comparison to move a step forward in durability quantification. Reinforced concrete beams made of traditional, high-performance and ultra-high-performance fibrereinforced concretes were prepared, sized $150 \times 100 \times 750 \mathrm{~mm}^{3}$. These beams were pre-cracked in flexion up to fixed strain levels in the tensioned zone to allow the analysis of the effect of the different cracking patterns on the self-healing capability. Afterwards, water permeability tests were performed before and after healing under water immersion. A modification of the water permeability test was also explored using chlorides to evaluate the potential protection of this healing in chloride-rich environments. The results show the superior durability and self-healing performance of UHPFRC elements.
\end{abstract}

\section{Introduction}

Concrete has a natural self-healing capability to seal small cracks, named autogenous healing, which is mainly produced by continuing hydration and carbonation [1]. At early age, continuing hydration of unhydrated cement particles is presumably the main cause for autogenous healing of cracks, while for older elements, carbonation would be the main mechanism [2]. Previous studies of the literature reported that UltraHigh-Performance Fibre-Reinforced Concrete (UHPFRC) and Engineered Cementitious Composites (ECC) are able to heal cracks for low damage levels, due to their cracking pattern with multiple micro-cracks and high cement content.

Regarding the self-healing properties of high performance concrete, in the mid-90s, Jacobsen et al. investigated autogenous healing of high-performance concrete with water/binder ratio of 0.40 and silica fume contents between 0 and $5 \%$ by the weight of cement. They achieved clear improvement in terms of resonance frequency values but not in terms of strength [3, 4]. Healing products were observed bridging cracks after the self-healing process and were identified as C-S-H [3]. Portlandite and ettringite were observed locally, as well. They analysed the samples with electron microscopy and only observed complete filling of the cracks under $5 \mu \mathrm{m}$. Granger et al. [5] analysed the recovery of stiffness and peak load of UHPC for specimens pre-cracked to have
$10 \mu \mathrm{m}$ of residual crack width, achieving stiffness recovery for specimens healed in water for 10 weeks. The stiffness of the filling products was close to those of primary $\mathrm{C}-\mathrm{S}-\mathrm{H}$. The slow recovery was thought as caused by the development of the mechanical properties of the new crystals or of the weakness zone between new crystals and primary $\mathrm{C}-\mathrm{S}-\mathrm{H}$.

The geometry of cracks, namely, crack width, length, depth, and cracking pattern (branched crack or accumulated crack) may determine their autogenous healing degree. Edvardsen [6, 7] reported that crack width is the parameter that most affects the healing process, since the narrower the cracks, the more efficient the autogenous healing. Therefore, by limiting and controlling the crack width, the potential for autogenous healing can be substantially improved. The use of fibrereinforced concrete to improve autogenous healing has focused mainly on Strain-Hardening Cementitious Composites (SHCC) or Engineered Cementitious Composites (ECC). These materials have a high volume of fibres, which permit the post-cracking stress redistribution and a ductile behaviour, thus featuring multiple cracking with very small cracks $(<0.05-0.07$ $\mathrm{mm}$ ). Yang et al. [8, 9] showed that ECC healed cracks could be of sufficient strength that new cracks are produced during the reloading stage, and the self-healed ECC material remained ductile. Their studies showed that, for small damage, specimens healed in cycles of

* Corresponding author: marroifl@upv.es 
water immersion and drying, recovered resonant frequency and stiffness. Ferrara et al. [10] evaluated autogenous healing in High Performance FibreReinforced Cementitious Composites (HPFRCCs) exposed to different conditioning environments, comparing different levels of crack openings. Their results showed that HPFRCCs are able to seal the cracks, and to recover their pristine level of mechanical performance, which was favoured by the presence of water, even in form of high air humidity or in the case of wet and dry cycles.

Several studies have been performed to study selfhealing in marine environments. One of those studies, performed by Darquennes et al. [11], studied the effect of self-healing of early age cracks ( $<28$ days), with cracks around $0.4 \mathrm{~mm}$, in mixes with blast-furnace slag, to limit chloride penetration and how chloride resistance could be improved by self-healing. The authors demonstrated that self-healing decreased the cumulative chloride concentration at the end of the migration test as well as the chloride concentration rate at steady state.

However, there is a lack of information on how autogenous healing of cracks could protect the interior of the concrete matrix, and its reinforcement, from the entrance of aggressive agents.

This research compares self-healing in a traditional concrete with a high-performance concrete and two types of ultra-high-performance concrete reinforced with steel fibres, pre-cracked to have comparable damage levels. A modification of the water permeability test performed in previous research [11, 12] was explored using a water column with chlorides, to evaluate the protection produced by healing underwater without chlorides, if the samples are exposed afterwards to aggressive chloride-rich environments.

The objectives of this study are:

- To provide a methodology to evaluate self-healing in Ultra-High-Performance Fibre-Reinforced Concrete based on the study of permeability in a cracked state;

- To characterize concrete durability by means of water permeability and chloride penetration tests;

- To analyse the cracking pattern, durability and selfhealing performance of Ultra-High-Performance FibreReinforced Concretes and traditional concrete types.

\section{Materials and methodology}

The concretes analysed in this study were Conventional Concrete (C20/25, named C1), High-Performance Concrete (C60/75, named $\mathrm{C} 2)$ and the two Ultra-HighPerformance Fibre-Reinforced Concretes (named C3 and C4). The experimental phase process consisted of casting the different concrete mixes, pre-cracking reinforced beams and to study the options for permeability tests for the evaluation of self-healing. Each concrete batch cast had a volume of 70 litres, to produce: 4 steel reinforced beams $100 \times 150 \times 750 \mathrm{~mm}^{3}, 2$ prisms $100 \times 100 \times 500 \mathrm{~mm}^{3}$ and 4 cubes $100 \times 100 \times 100 \mathrm{~mm}^{3}$.

\subsection{Materials and mix design}

The mixes were designed to represent two types of traditional concretes without fibres, with different water/cement $(w / c)$, water/binder $(w / b)$ ratios and cement contents to compare the effects of the composition, and two different UHPFRCs, with different fibre contents, to produce different deformation and crack responses. Table 1 shows the composition of all these mixes.

The cement used was CEM I 42,5 R-SR5 from Lafarge, and the undensified microsilica from Elkem. Different aggregates were used according to the type of concrete produced. For traditional and high-performance concretes $(\mathrm{C} 1$ and $\mathrm{C} 2)$ gravel of the categories $7 / 12$ and $4 / 7\left(\mathrm{~d}_{\min } / \mathrm{D}_{\max }\right)$ and natural sand were used in the mix. In the traditional concrete $\mathrm{C} 1 \mathrm{mix}$, limestone filler was also added to compensate for the lack of fines of this sand. In UHPFRC fine silica sand $(0 / 0.6 \mathrm{~mm})$ and medium silica sand $(0 / 1.2 \mathrm{~mm})$ were used. In UHPFRC mixes, silica flour from Quarzfin U-S 500 was used for the finer fractions. Sika ViscoCrete-20 HE superplasticizer was used to achieve the high workability of these selfcompacting mixes. In addition, in the UHPFRCs mixes, high tensile strength micro steel fibres $0.22 \times 13 \mathrm{~mm}$ were used, while in traditional and high-performance concrete, no fibres were added. These fibres provided the mix with high ductility and multi-cracking behaviour, increasing compressive strength. In addition, the fibres contributed to keeping crack width fixed after the pre-cracking and to the stability of the samples during the permeability tests.

Table 1. Mix design of the four concrete types.

\begin{tabular}{|l|c|c|c|c|}
\hline \multicolumn{1}{|c|}{$\mathrm{kg} / \mathrm{m}^{3}$} & C1 & C2 & C3 & C4 \\
\hline Cement I 42.5 R-SR5 & 350 & 450 & 800 & 800 \\
\hline Silica Fume & & 50 & 175 & 175 \\
\hline Water & 192 & 160 & 160 & 160 \\
\hline$w / c$ & 0.591 & 0.356 & 0.200 & 0.200 \\
\hline$w / b$ & 0.591 & 0.320 & 0.164 & 0.164 \\
\hline Aggregate 7/12 & 600 & 200 & & \\
\hline Aggregate 4/7 & 300 & 600 & & \\
\hline Natural sand & 950 & 950 & & \\
\hline Limestone filler & 60 & & & \\
\hline $\begin{array}{l}\text { Siliceous sand - } \\
\text { medium }\end{array}$ & & & 565 & \\
\hline Siliceous sand - fine & & & 302 & 1092 \\
\hline Siliceous sand - flour & & & 225 & \\
\hline Short fibres & & & 160 & 130 \\
\hline Plasticizer Sika 20 HE & & 3.5 & 30 & 30 \\
\hline
\end{tabular}

\subsection{Concrete characterization}

Control tests were performed on cubes and prisms with the purpose of evaluating the difference between mixes (C1, C2, C3 and C4). For each concrete batch, four $100 \times 100 \times 100 \mathrm{~mm}^{3}$ cubic specimens were cast to determine the compressive strength at 28 days, according to EN 12390-3, applying a load rate of $8 \mathrm{kN} / \mathrm{s}$ and 0.8 $\mathrm{MPa} / \mathrm{s}$. The average results of compressive strength obtained are displayed in Table 2.

For mixes C3 and C4, two $100 \times 100 \times 500 \mathrm{~mm}^{3}$ prismatic specimens were cast to study their tensile 
Table 2. Control tests results: compressive strength and tensile behaviour for UHPFRCs.

\begin{tabular}{|c|c|c|c|c|c|c|c|c|c|}
\hline \multirow{2}{*}{ Concrete } & $\begin{array}{c}\text { Compr. } \\
\text { strength }\end{array}$ & \multicolumn{2}{|c|}{ Flexural strength } & \multicolumn{6}{|c|}{ Inverse Analysis - Tensile constitutive model } \\
\hline & $\mathbf{f}_{\mathbf{c m}}$ & $\boldsymbol{\sigma}_{\text {loc }}$ & $\boldsymbol{\delta}_{\mathbf{l o c}}$ & $\mathbf{f}_{\mathbf{t}}$ & $\mathbf{f}_{\text {tu }}$ & $\mathbf{e}_{\mathbf{t u}}$ & $\mathbf{E}$ & $\mathbf{W}_{\mathbf{d}}$ & $\mathbf{W}_{\mathbf{0}}$ \\
\hline Code & $M P a$ & $M P a$ & $m m$ & $M P a$ & $M P a$ & $-10^{-3}$ & $M P a$ & $m m$ & $m m$ \\
\hline C1 & 38.5 & - & - & - & - & - & - & - & - \\
\hline C2 & 82.3 & - & - & - & - & - & - & - & - \\
\hline C3 & 149.6 & 18.22 & 0.66 & 9.49 & 6.83 & 2.356 & 47800 & 1.60 & 2.40 \\
\hline C4 & 121.1 & 16.66 & 0.70 & 7.75 & 6.84 & 2.526 & 39100 & 1.92 & 2.89 \\
\hline
\end{tabular}

properties using a simplified inverse analysis method from a four-point bending test on unnotched specimens. The method followed was proposed in [13], and defines the tensile constitutive behaviour as a function of six parameters: elastic modulus $(\mathrm{E})$, cracking strength $\left(\mathrm{f}_{\mathrm{t}}\right)$, ultimate cracking strength $\left(\mathrm{f}_{\mathrm{tu}}\right)$ and its associated strain $\left(\varepsilon_{\mathrm{t}, \mathrm{u}}\right)$, crack opening at the intersection of the line that defines the initial slope to the $\mathrm{w}$ axis $\left(\mathrm{w}_{0}\right)$ and the characteristic crack opening $\left(l_{\mathrm{f}} / 4\right)$, being $l_{\mathrm{f}}$ the fibre length. Table 2 shows the constitutive behaviour in tensile obtained for $\mathrm{C} 3$ and $\mathrm{C} 4$ mixes. As expected, the C3 mix reported a tensile strength value of about $22 \%$ higher than the $\mathrm{C} 4$ due to its higher content of steel fibres.

\subsection{Pre-cracking method}

In this work, for the study of self-healing, reinforced concrete beams were used. The reinforcement introduced in the samples consisted of $2 ø 8$ lower reinforcing bars and $6 ø 6$ stirrups to avoid shear failure during the precracking stage. These beams were pre-cracked afterwards to the desired cracking level at the age of 28 days. The dimensions, number and location of the reinforcing bars and stirrups are shown in Fig. 1, as well as the relative distances and points of support when performing the four-point bending test.

Before starting the test, two rows of small discs were glued to the side of each sample, setting up an upper row and a lower row, to be able to measure the strain variation at two different levels with a Demountable Mechanical Strain Gauge (DEMEC) before, during and after every loading-unloading cycle.

The procedure for controlling crack width was based on calculating the strain at six intervals separated by initial distance of $100 \mathrm{~mm}$. First, the change in length between the points with the DEMEC was detected and then strain $(\varepsilon)$ was calculated through the following formula:

$$
\varepsilon=1000 \cdot\left(\Delta \mathrm{L}_{0}-\Delta \mathrm{L}_{\mathrm{x}}\right) / \mathrm{l}_{0}
$$

Where:

$-\varepsilon$ is the strain level expressed in \%o

- $\Delta \mathrm{L}_{0}$ is the length between 2 DEMEC points at zero load, expressed in $\mathrm{mm}$

- $\Delta \mathrm{L}_{\mathrm{x}}$ is the length between 2 DEMEC points at $\mathrm{x}$ load, expressed in $\mathrm{mm}$

- $\mathrm{l}_{0}$ is the reference length of $100 \mathrm{~mm}$

This method allows control of the resulting strain at two different heights: at the lower row (points 1-5) and at the upper row (points 6-10). The location of these measuring points is displayed in Fig 2, where each couple of points (such as 6-8, 7-9 or 8-10) were located at a distance of $100 \mathrm{~mm}$. The lower row (points 1-5) were located at the reinforcement level, while the upper row (points 6-10) were located at middle depth of the beam.

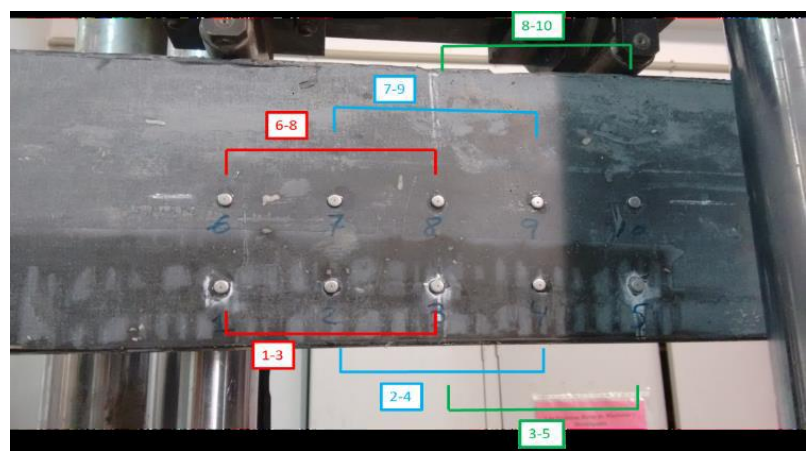

Fig. 2 - DEMEC points glued to the beam to measure strain.
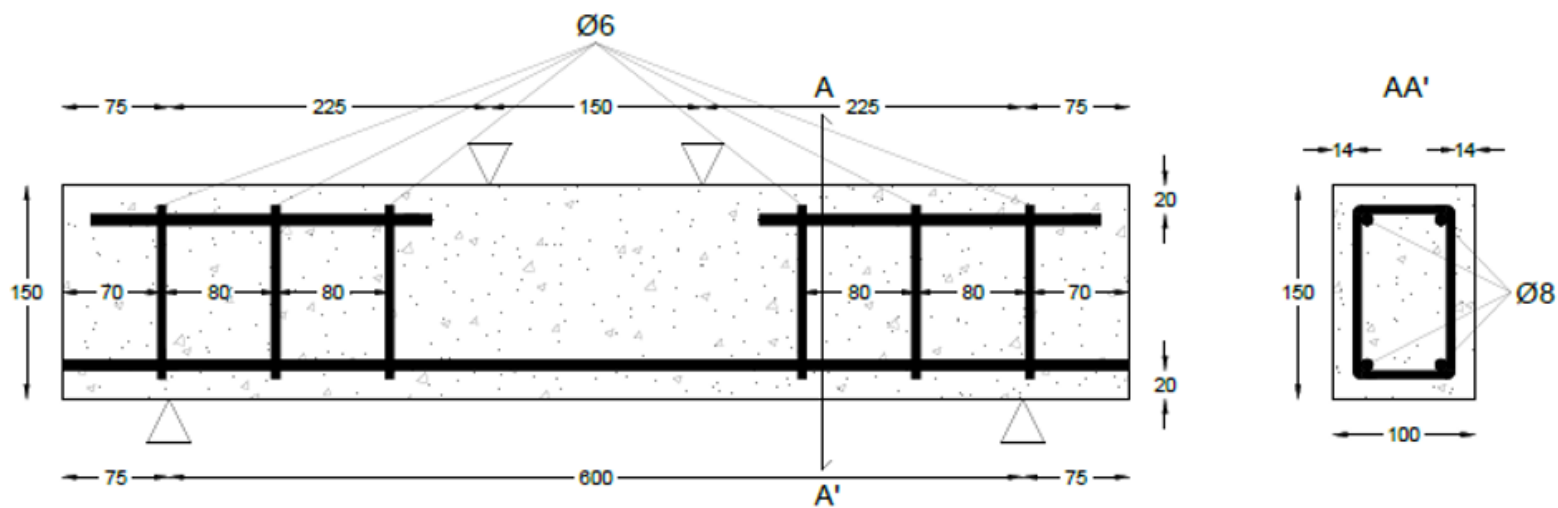

Fig. 1 - Reinforced beam model, dimensions in millimetres. 
The cracking target was based on achieving a large crack, or rather, a residual average strain $\varepsilon_{\text {avg }}$ between $1 \%$ and $2 \%$ after unloading at the lower DEMEC row (reinforcement level). Considering the different values of strain obtained in the intervals $(1-3,2-4,3-5)$ between the DEMEC points due to the random appearance of the cracks and to give homogeneity to the results, the condition of large crack was considered reached when the averaged strain of the three intervals of the lower DEMEC row exceeded the value of $1.5 \%$.

During loading, the strain value of $2 \%$ was frequently reached and exceeded. This large crack condition represents a condition beyond the service limit state, since, it is the value in which rebars start to yield.

The procedure followed with the UHPFRCs (C3 and C4) during the controlled cracking consisted of gradually increasing the load from zero, stopping at certain loading values, where the change in length between the DEMEC points was measured and consequently, through a spreadsheet, strain (\%o) was obtained in each interval (1$3,2-4 \ldots)$. Strain was usually measured at zero tons (reference condition of zero strain), 6 tons, 8 tons and 10 tons. After reaching 10 tons, loading-unloading cycles were performed, increasing after 0.5 tonnes in each cycle until reaching the target strain $\left(\varepsilon_{\text {avg }} \geq 1.5 \%\right.$ ). These loading-unloading cycles were needed to reach the desired deformation values after unloading, since UHPFRCs mixes recovered a great part of their deformation. This procedure allowed the desired target to be reached with an average residual strain value close to $1.5 \%$ at the lower row and $<1.0 \%$ at the upper row.

For traditional and high-performance concretes $(\mathrm{C} 1$ and $\mathrm{C} 2$ ) the procedure followed was equivalent but reaching lower loads because of their lower flexural strength. A maximum load of 6 tons was reached, but due to the greater difficulty in controlling the crack opening with this type of concrete, very high residual strains were achieved, in the order of $3 \%$ - 4\%o. In fact, under the same load, in traditional concrete, the strain value turns out to be very different in the intervals belonging to the same DEMEC line. On the contrary, all UHPFRC beams and pair of DEMEC points showed similar strains. This is produced by the cracking pattern of traditional and high-performance concretes without fibres, characterized by only few cracks. When these cracks appear, their location is unpredictable. Those locations where strain values were higher were where cracks appeared.

The strain values obtained with DEMEC points were complemented with measurements made with an optical microscope at either the upper or lower row levels to correlate strain rates and crack widths, a critical relation for the evaluation of the durability parameters and the entrance of aggressive agents.

\subsection{Self-healing evaluation}

After this pre-cracking stage, the crack width of all beams was evaluated and afterwards, the beams were sawed to obtain smaller specimens and perform permeability tests before and after healing.

\subsubsection{Preparation of samples}

After the pre-cracking stage, cracks were all located in the central section of the beam while the lateral portions of the beam remained uncracked. For this reason, beams were sawn to obtain four smaller specimens of the size of $150 \times 150 \times 50 \mathrm{~mm}^{3}$ to perform the permeability tests for the evaluation of self-healing (Fig 3).

Since some of the tests performed to evaluate selfhealing are destructive, The A and B samples were distributed as follows: A samples were tested before healing and B samples after healing. These A and B samples were twin samples coming from the same section of the beam and thus had the same deformation.

\subsubsection{Adapting water permeability tests}

Previous tests performed for traditional fibre-reinforced concretes [3, 4] using a high-pressure water permeability test showed the correlation between higher values of damage and higher values of water flow. Thus, this highpressure water-permeability test was used as a first approach for this experimental campaign.

In this case, however, traditional concretes showed specific features during the preliminary tests. When performing high-pressure water permeability tests to $\mathrm{C} 1$ and $\mathrm{C} 2$ concretes, water pressure and the compression applied to fix the sample to the plates from the device, produced the breakage of some of the specimens. In addition, since the cracks passed through the complete section of the sample, they would need complete sealing of the lateral cracks to permit water to flow only through the interior of the sample.

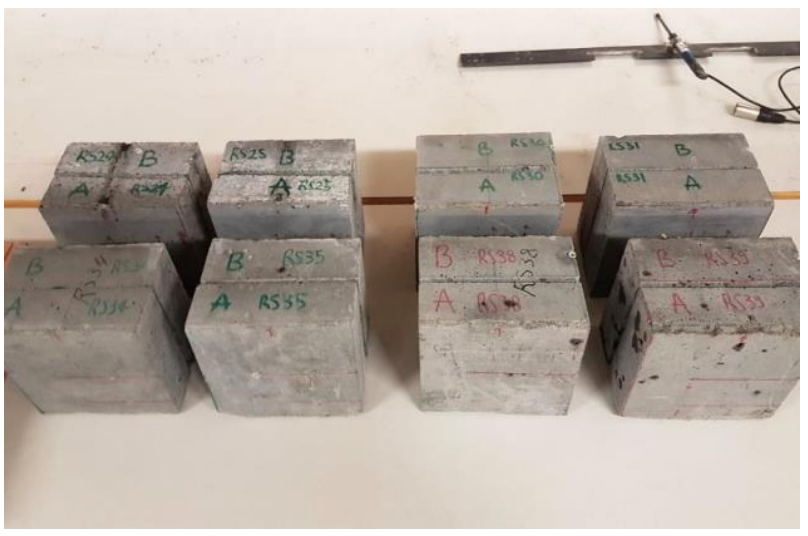

Fig. 3 - Prismatic specimens obtained after sawing the reinforced beams.

For these reasons, to evaluate self-healing capability in traditional concrete, it was decided to perform a water permeability test in low-pressure conditions. This method consisted of using a PVC tube $\left(\varnothing_{\mathrm{e}}=75 \mathrm{~mm}\right.$, length around $60 \mathrm{~cm}$ ) glued to the specimens with a resin (in this case, Sikaflex 11 FC). This low-pressure water permeability test is based on calculating the time taken by a $50 \mathrm{~cm}$ column of water to empty, passing completely through the cracked specimen. If the cracks were too small to allow the column to empty within a few hours, it was decided to calculate the decrease in 
water-height of the water column in a fixed time (3 hours).

This low-pressure water permeability test has been performed only on the traditional and high-performance concrete samples ( $\mathrm{C} 1$ and $\mathrm{C} 2$ ), and on single cracks, since its cracking pattern produces only localized cracks. Thanks to this test, it is possible to measure the degree of permeability of these cracked specimens. With this test, the same samples can be tested a second time after healing takes place and thus direct assessments on autogenous healing effects can be performed.

In the case of UHPFRC samples (C3 and C4), they were able to resist the high-pressure water permeability test; however, water was not passing through their cracks. This happened despite the high strain values obtained during the pre-cracking stage. In fact, all the UHPFRCs tested had no water passing through the specimens in 5 minutes of testing time at the pressure of 2 bars. Furthermore, no moisture was even detected at the base of the specimens at the end of the tests, proof that water was not able to cross the cracked section. Only in the case of one of the specimens, some drops of water were observed coming out, however, it was not possible to measure them due to their small weight, approx. from 0 to 10 grams (see Table 3 ).

Because of that, another modified water permeability test was proposed. This test is based on the use of sodium chloride and its reactivity to silver nitrate as an indicator to show where water was able to penetrate. This test is destructive and thus the same samples cannot be tested a second time after healing.

Table 3. Results of high-pressure water permeability test performed on UHPFRCs samples.

\begin{tabular}{|c|c|c|}
\hline Concrete mix & $\begin{array}{c}\text { Average crack } \\
\text { width (mm) }\end{array}$ & $\begin{array}{c}\text { Amount of water } \\
\text { passing through } \\
\text { the sample }\end{array}$ \\
\hline $\mathrm{C} 3$ & 0.025 & - \\
\hline $\mathrm{C} 3$ & 0.025 & - \\
\hline $\mathrm{C} 4$ & 0.025 & - \\
\hline $\mathrm{C} 4$ & 0.050 & $0-10$ grams \\
\hline
\end{tabular}

This proposed test consists of a version of the lowpressure water permeability test, using the same PVC tubes with an outer diameter of $75 \mathrm{~mm}$. Every tube was filled with salt water with a concentration of $35 \mathrm{~g}$ $\mathrm{NaCl} /$ litre, and the salted water column was left for 3 days over the samples. The water level was controlled every working day, so it remained around $50 \mathrm{~cm}$, and in case of visible evaporation, tap water was added to maintain the same pressure level. After three days, the tube was removed, and the specimen was cut transversely to the direction of the cracks with a circular saw for concrete (Fig. 4).

In order to measure the chloride penetration depth, firstly, specimens were left to dry and afterwards a silver nitrate $\left(\mathrm{AgNO}_{3}\right)$ solution with a concentration of 0.1 mol/1 was sprayed on the both cracked surface where the cut was made. After the chemical reaction, the area colored in white is the area of interest, where silver ions reacted with the chloride ions, while the brown one is formed when the silver ions react with the hydroxyl compounds.

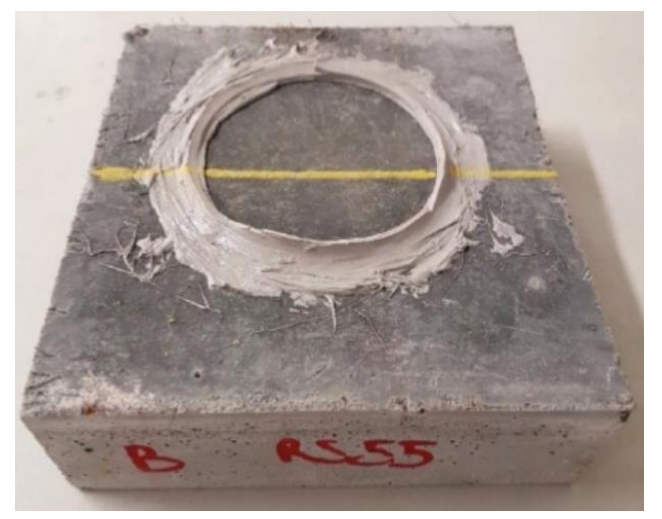

Fig. 4 - Specimen after performing chloride penetration test with the rests of resin and the transversal section that will be cut marked.

\subsubsection{Self-healing conditions}

To promote autogenous healing, specimens were left immersed in a tank full of deionized water for 28 days. This healing time was considered enough for producing most of the autogenous healing reactions, in part, due to the small size of the cracks.

The water was chosen to be deionized water from a cationic and anionic resin (proportion of $60 \%$ anionic of strong base and $40 \%$ cationic of strong acid) to avoid the presence of chlorides in the tap water that could condition the results of the chloride penetration tests after healing.

As previously explained, the twin specimens (B sides) were immersed in water to heal, since the procedure for detecting chloride penetration did not allow the same sample to be tested twice. After one month in water, it was expected that cracks in the specimens had closed or partially closed on the surface, thus being able to assess a recovery of the durability properties.

\section{Results}

This section shows the results obtained when analysing the cracking pattern and the autogenous healing capability of these four concrete types using the aforementioned permeability tests.

\subsection{Cracking pattern}

UHPFRCs showed higher mechanical performance during tests and a cracking pattern with multiple microcracks. After unloading they did not show visible localized cracks, whereas traditional concretes did. In fact, while on the one hand traditional concrete presented only few visible cracks, measurable through the use of a crack width meter, UHPFRC on the other hand featured 
a large number of widespread cracks, not visible to the naked eye. Then, the positions of the cracks were analysed with the use of the microscope and were marked on the samples.

Table 4 shows the differences in deformation and number of cracks obtained for the two beams tested per concrete type. In general, C4 specimens, compared to C3 specimens, at the same maximum load reached or even lower, always suffered greater deformations, due to their lower fibre content, but with a comparable value of average number of residual cracks and average crack width.

When comparing the appearance of the first visible crack under load between traditional concrete and UHPFRC, it has been observed that in the former the first crack appeared at about 2 tons whereas in the latter at about 8 tons. This cracking behaviour of UHPFRC is achieved thanks to its particular mix design consisting of small size of the constituents, high cement content and steel fibres capable of limiting crack opening. The amount of fibres in the mix turned out to be of great importance in the control of crack opening. In fact, the C4 mix, having a lower amount of fibres $\left(130 \mathrm{~kg} / \mathrm{m}^{3}\right.$ instead of $160 \mathrm{~kg} / \mathrm{m}^{3}$ of the $\mathrm{C} 3 \mathrm{mix}$ ) showed lower flexural strength and lower performance in terms of control of the crack opening.

Fig 5 and Fig 6 show examples of pictures of the cracks obtained for a traditional concrete and a UHPFRC type, respectively, taken at the same magnification level. This difference in crack width will have significant effects on the transport properties, durability and their autogenous healing potential

Table 4. Crack analysis results after pre-cracking all the reinforced beams

\begin{tabular}{|c|c|c|c|c|c|c|c|}
\hline \multirow{3}{*}{ Type } & \multirow[b]{2}{*}{$\begin{array}{l}\text { Max. } \\
\text { Load }\end{array}$} & \multicolumn{3}{|c|}{ DEMEC 1-5 } & \multicolumn{3}{|c|}{ DEMEC 6-10 } \\
\hline & & $\varepsilon_{\text {avg }}$ & $\mathrm{N}^{\circ}$ & $\omega_{\text {avg }}$ & $\varepsilon_{\text {avg }}$ & $\mathrm{N}^{\circ}$ & $\omega_{\text {avg }}$ \\
\hline & Ton & $\%$ & Hacks & $m m$ & $\%$ & Clacks & $m m$ \\
\hline \multirow{2}{*}{ C1 } & 6.2 & 3.70 & 2 & 0.200 & 1.66 & 2 & 0.100 \\
\hline & 6.0 & 2.95 & 2 & 0.200 & 1.26 & 2 & 0.100 \\
\hline \multirow{2}{*}{$\mathrm{C2}$} & 6.6 & 4.33 & 3 & 0.150 & 2.56 & 3 & 0.100 \\
\hline & 6.5 & 4.35 & 2 & 0.250 & 2.78 & 2 & 0.150 \\
\hline \multirow{2}{*}{ C3 } & 12.0 & 1.40 & 12 & 0.025 & 0.81 & 12 & 0.015 \\
\hline & 13.0 & 1.55 & 11 & 0.025 & 0.90 & 11 & 0.015 \\
\hline \multirow{2}{*}{ C4 } & 11.0 & 2.26 & 20 & 0.025 & 1.21 & 11 & 0.015 \\
\hline & 11.0 & 2.19 & 14 & 0.050 & 1.56 & 10 & 0.030 \\
\hline
\end{tabular}

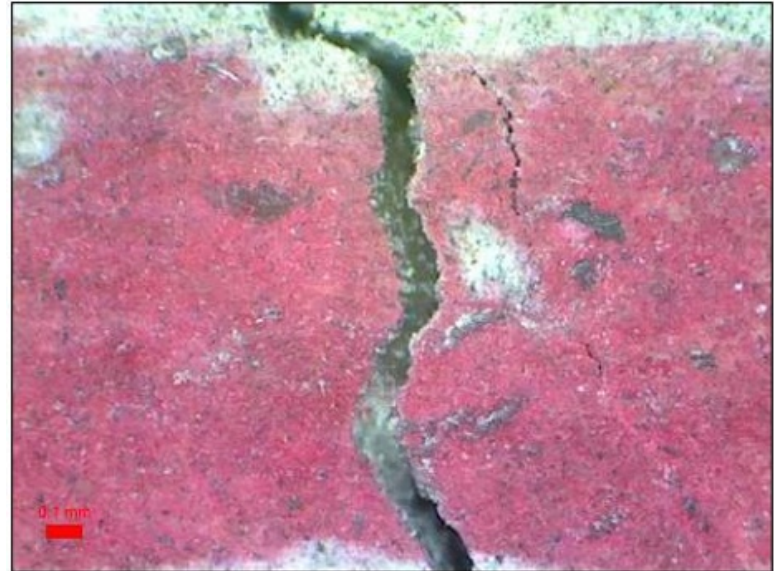

Fig. 5 - Crack of $0.1 \mathrm{~mm}$ in traditional concrete at $200 \mathrm{x}$ magnification

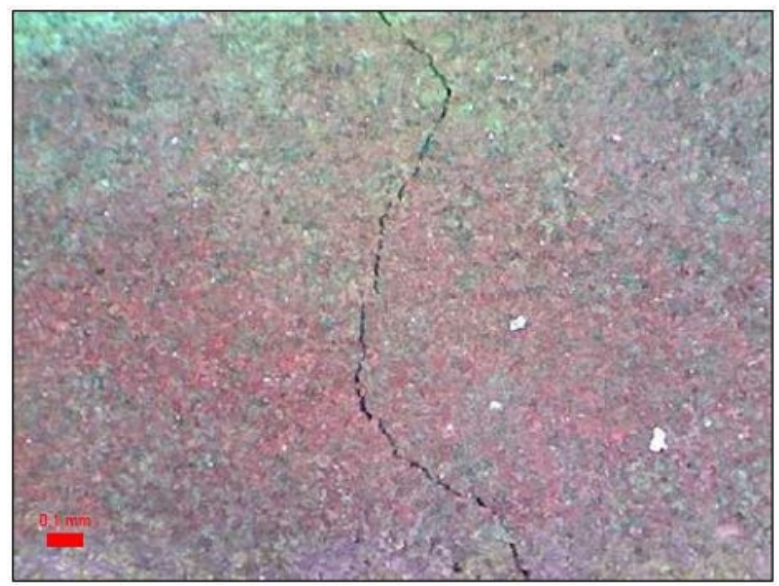

Fig. 6 - Crack of $0.01 \mathrm{~mm}$ in an UHPFRC at 200x magnification

\subsection{Water permeability}

Water permeability tests performed as described in the subsection "2.4.2 Adapting water permeability tests" showed that UHPFRCs samples, despite the large cracking level corresponding to an average crack width of $0.025 \mathrm{~mm}$, did not allow the movement of water through the cracks. In addition, traditional and highperformance concrete types, without fibres, had stability problems with the high-pressure water permeability device. Thus, this section shows the results obtained with the low-pressure water permeability for concretes without fibres ( $\mathrm{C} 1$ and $\mathrm{C} 2)$ and chloride penetration water permeability test for UHPFRCs (C3 and C4).

\subsubsection{Low-pressure water permeability}

This test was used to evaluate autogenous healing in four samples of concrete without fibres. two of the samples were of conventional concrete (C1-1 and C1-2) and two of high-performance concrete (C2-1 and C2-2). From the results obtained for water level decrease and the time taken, water flow can be calculated. The results obtained with the four specimens tested with this test are presented in Table 5. 
Before starting the tests, an additional crack measurement was made on the specimens, to verify if crack width was kept the same compared to the previous analysis, since the sawing process could have modified the crack width. It was noticed that cracks were wider in the inner section of the beam, namely, at the interface between the sample $\mathrm{A}$ and $\mathrm{B}$, where the cut was made, whereas on the surface cracks were around $0.050 \mathrm{~mm}$ narrower. These results are also displayed in Table 5.

Table 5. Results of high-pressure water permeability test performed on UHPFRCs samples.

\begin{tabular}{|c|c|c|c|c|}
\hline & \multicolumn{2}{|c|}{ Crack width } & \multicolumn{2}{c|}{$\begin{array}{c}\text { Water flow passing } \\
\text { through the sample } \\
\text { (gr/min) }\end{array}$} \\
\hline $\begin{array}{c}\text { Specimen } \\
\text { tested }\end{array}$ & $\begin{array}{c}\text { Surface 1 } \\
(\mathbf{m m})\end{array}$ & $\begin{array}{c}\text { Surface 2 } \\
(\mathbf{m m})\end{array}$ & $\begin{array}{c}\text { Before } \\
\text { healing }\end{array}$ & $\begin{array}{c}\text { After 28d } \\
\text { healing }\end{array}$ \\
\hline $\mathrm{C} 1-1$ & $\begin{array}{c}0.05+ \\
0.15\end{array}$ & 0.20 & 0.922 & 1.106 \\
\hline $\mathrm{C} 1-2$ & $\begin{array}{c}0.05+ \\
0.15\end{array}$ & 0.20 & 0.092 & 0.000 \\
\hline $\mathrm{C} 2-1$ & $0.1+0.15$ & 0.30 & 12.763 & 15.802 \\
\hline $\mathrm{C} 2-2$ & $0.1+0.15$ & 0.30 & 11.061 & 8.480 \\
\hline
\end{tabular}

Regarding the recovery of properties due to autogenous healing, neither traditional nor high-performance concretes showed noteworthy improvements after performing the low-pressure water permeability tests. The results obtained show that half of the samples experienced slight reductions in the water permeability test due to autogenous healing, but half of them experienced slight increases. Thus, these results indicate the high variability and low reliability of autogenous healing in traditional concrete types with cracks around $0.20 \mathrm{~mm}$.

\subsubsection{Water permeability through chloride penetration}

This test was used to evaluate autogenous healing in four samples of UHPFRCs. two of the samples from C3 mix and two of them from $\mathrm{C} 4 \mathrm{mix}$.

The results achieved indicate that, despite the small size of the cracks (around $0.025 \mathrm{~mm}$ ), water containing chlorides was able to penetrate through the matrix in both, C3 and C4 mixes. Thus, in both cases, 3 days of exposure of salted-water, which simulates the exposure conditions of a marine environment, produced a considerable penetration of chlorides through the cement matrix.

Fig. 7 displays pictures showing the results obtained for $\mathrm{C} 3$ and $\mathrm{C} 4$ mixes before and after healing. In these pictures, chloride penetration is displayed as the white or lighter areas.

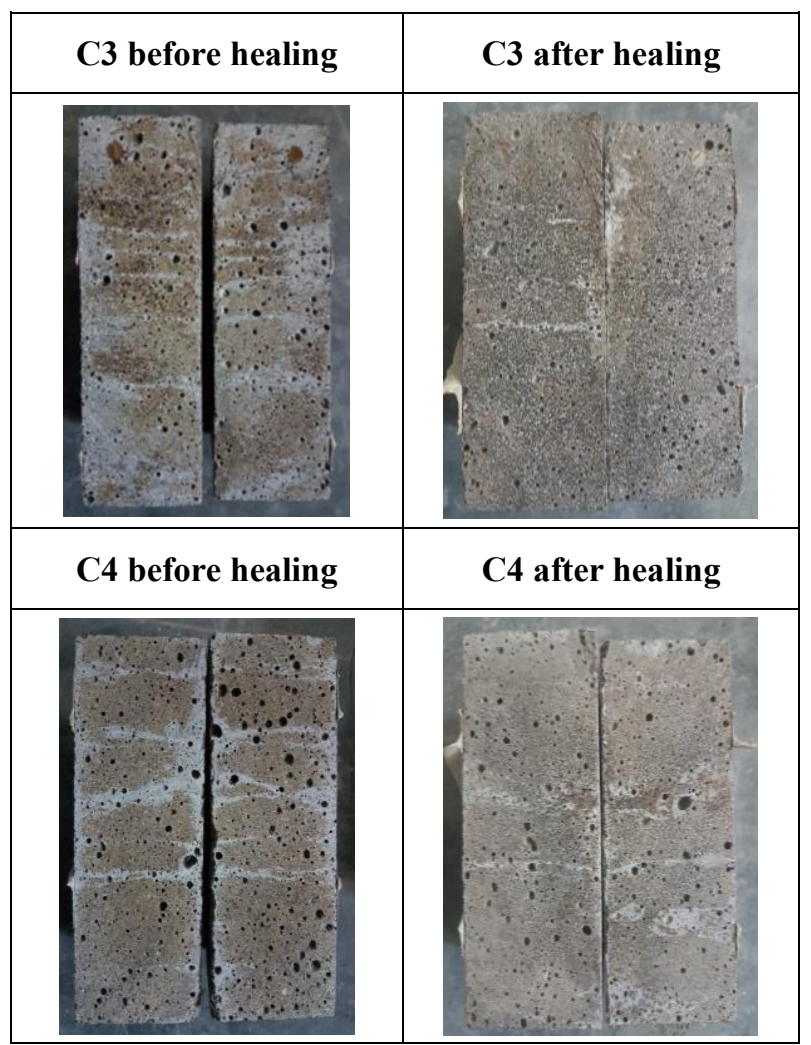

Fig. 7 - Comparison between chloride penetration in C3 and $\mathrm{C} 4$ before and after healing

Analysing the results obtained before healing, the $\mathrm{C} 4$ mixes showed a greater chloride penetration through the concrete matrix than the $\mathrm{C} 3$ ones, which is demonstrated by the bigger visible chloride area. This is due to the different composition of the mixes, mainly due to the difference in fibre contents (lower in C4). In addition, in the $\mathrm{C} 3$ mixes there is a much more widespread penetration of chloride, while in the mixes of $\mathrm{C} 4$ it is possible to note the clear presence of localized cracks.

Comparing the results obtained before and after healing for these two UHPFRCs mixes, it is clearly demonstrated that the precipitates closing the cracks of C3 mixes were able to stop salted-water penetration, and thus, provide a good protection against corrosion. The C4 mix provided a good improvement, but there were still a couple of cracks passing through the section of the sample, showing that they had lower autogenous healing capability and/or protection against chloride penetration.

Regarding the visual crack closure, it should be mentioned that most of the UHPFRCs narrower cracks $(<0.1 \mathrm{~mm})$ were closed or partially closed, with a yellow precipitate inside the cracks due to the corrosion of the steel fibres. However, in the traditional and highperformance concretes, no visual crack closure was detected due to their greater cracks' width. 


\section{Conclusions and future work}

This work aimed to propose water-permeability methodologies to evaluate self-healing of concrete samples that present different types of cracking patterns and sizes. The following related conclusions can be drawn:

The methodology proposed in this work consists of easy to implement steps in the laboratory, that allow the evaluation of self-healing in traditional and UHPFRCs. The phases of the methodology are: pre-cracking, where the ability to control the cracking procedure reaching the desired level of strain has been demonstrated; the phase of crack analysis, where by means of optical microscope together with software for the image analysis it is possible to detect and measure every crack; and finally the permeability tests, which have proved to be able to detect the variation in durability properties due to the crack healing.

- Concrete samples without fibres could be tested with the low-pressure water permeability test, by the evaluation of the water flow passing through the cracks before and after healing took place. In these samples, autogenous healing is not able to produce significant improvements of the durability.

- UHPFRC samples were able to totally prevent the entry of water liquids in the low and high-pressure water permeability tests. However, with the chloride penetration water permeability test, the results indicated the clear entrance of salted-water. In these samples, autogenous healing displayed a clear improvement in the water permeability test proposed, which was even greater in the mixes with higher contents of fibres, and thus, lower crack width for the same strain level.

Further studies are still being performed that will include additional cracking levels as well as self-healing promoters.

This project has received funding from the European Union's Horizon 2020 research and innovation programme under grant agreement No. 760824, project ReSHEALience.

\section{References}

1. De Belie, N., et al. 2018 "A Review of Self-Healing Concrete for Damage Management of Structures." Advanced Materials Interfaces (2018): 1800074.

2. K. Van Tittelboom and N. De Belie, "Self-Healing in Cementitious Materials-A Review," Materials, vol. 6, pp. 2182-2217, 2013.

3. Jacobsen, S., Granl, H.C., Sellevold, E.J. \& Bakke, J.A., 1995. High Strength Concrete - Freeze/Thaw Testing and Cracking. Cement and Concrete Research, 25(8), pp.1775-80.

4. Jacobsen, S. \& Sellevold, E.J., 1996. Self Healing of High Strength Concrete after Deterioration by Freeze/Thaw. Cement and Concrete Research, 26(1), pp.55-62.

5. Granger, S., Loukili, A., Pijaudier-Cabot, G. \& Chanvillard, G., 2005. Mechanical characterization of the self-healing effect of cracks in Ultra High
Performance Concrete (UHPC). In Proceedings Third International Conference on Construction Materials, Performance, Innovations and Structural Implications, ConMat, 5, pp.22-24.

6. Edvardsen, C.K., 1996. Wasserdurchlässigkeit und Selbstheilung von Trennrissen in Beton. Berlin: Beuth.

7. Edvardsen, C., 1999. Water Permeability and Autogenous Healing of Cracks in Concrete. ACI Materials Journal, 96(4), pp.448-54.

8. Yang, Y., Lepech, M.D., Yang, E.-H. \& Li, V.C., 2009. Autogenous healing of engineered cementitious composites under wet-dry cycles. Cement and Concrete Research, 39, pp.382-90.

9. Yang, Y., Yang, E.-H. \& Li, V.C., 2011. Autogenous healing of engineered cementitious composites at early age. Cement and Concrete Research, 41, pp.176-83.

10. Ferrara, L., Krelani, V., Moretti, F., Roig-Flores, M. and Serna-Ros, P., 2017. Effects of autogenous healing on the recovery of mechanical performance of High Performance Fibre Reinforced Cementitious Composites (HPFRCCs): part 1. Cement and Concrete Composites, 83, pp.76-100.

11. Darquennes, A., Olivier, K., Benboudjema, F. and Gagné, R., 2016. Self-healing at early-age, a way to improve the chloride resistance of blast-furnace slag cementitious materials. Construction and Building Materials, 113, pp.1017-1028.

12. Roig-Flores, M., Moscato, S., Serna, P. \& Ferrara, L., 2015. Self-healing capability of concrete with crystalline admixtures in different environments. Construction and Building Materials, 86, pp.1-11.

13. Roig-Flores, M., Pirritano, F., Serna, P. \& Ferrara, L., 2016. Effect of crystalline admixtures on the self-healing capability of early-age concrete studied by means of permeability and crack closing tests. Construction and Building Materials, 114, pp.44757.

14. López, J.Á., Serna, P., Navarro-Gregori, J. and Coll, H., 2016. A simplified five-point inverse analysis method to determine the tensile properties of UHPFRC from unnotched four-point bending tests. Composites Part B: Engineering, 91, pp.189-204. 